\title{
Joubert syndrome
}

\author{
Lakshmikanth Halegubbi Karegowda, Poonam Mohan Shenoy, Smiti Sripathi, \\ Mugil Varman
}

Department of Radiodiagnosis, Kasturba Medical College, Manipal, Manipal, Karnataka, India

\section{Correspondence to}

Dr Poonam Mohan Shenoy, drpoonamshenoy@gmail.com

Accepted 19 February 2014

\section{DESCRIPTION}

A 10-year-old boy was referred to our department for evaluation of global developmental delay, cognitive impairment, hypotonia, large head size and poor development of speech. He was born to consanguineous parents after a full-term pregnancy. There was no history of antenatal or neonatal complications. On examination, he had short stature, squint and hearing loss in the right ear. There were no dysmorphic facial features or polydactyly. The fundus examination and the rest of the systemic examination were normal. The patient has two other siblings who have normal cognitive development.

A CT scan revealed elongated and thickened superior cerebellar peduncles with widened interpeduncular fossa consistent with the 'Molar tooth' sign (figures 1 and 2). The vermis was hypoplastic, resulting in an enlarged and deformed fourth ventricle with a 'batwing appearance' (figures 3 and 4). The rest of the cerebrospinal fluid (CSF) spaces were normal. The posterior fossa appeared enlarged with increased size of the prepontine cistern. The cerebellar hemispheres and corpus callosum were normal. There were no migration disorders, ventriculomegaly or abnormalties of the brainstem.

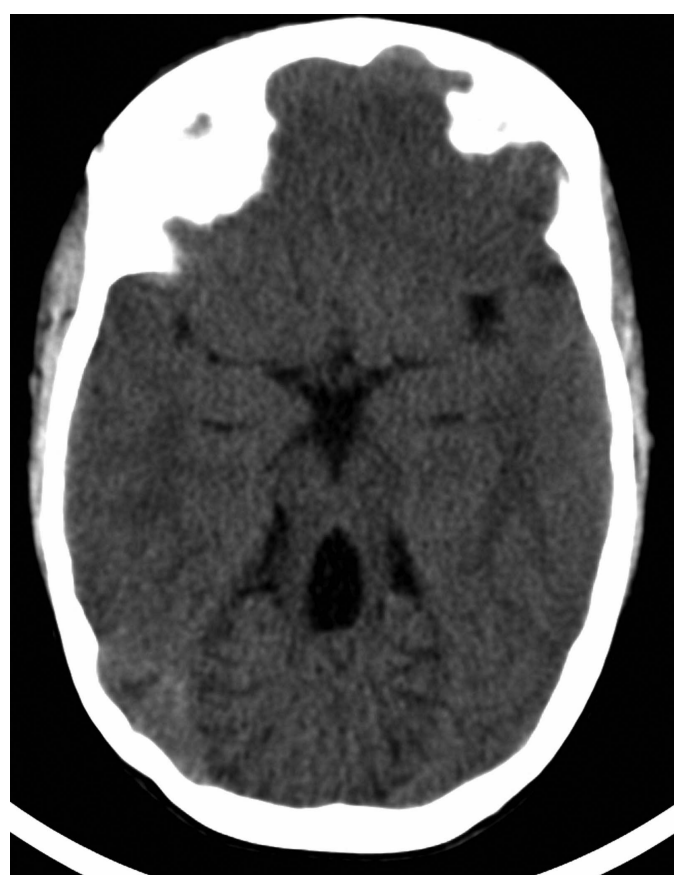

Figure 1 Axial CT section showing thickened parallel superior cerebellar peduncles with widened interpeduncular fossa giving the 'molar tooth' appearance.

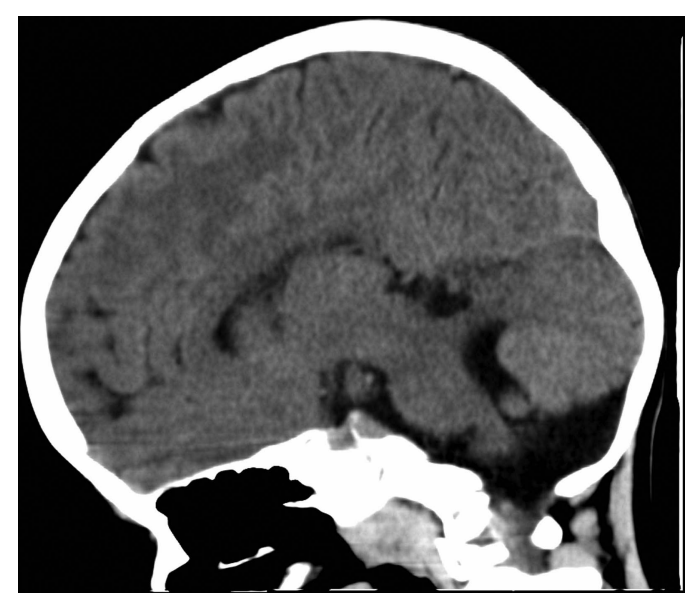

Figure 2 Sagittal CT section showing a horizontal orientation of the thickened superior cerebellar peduncle.

Joubert syndrome is a rare autosomal recessive congenital disorder. It is associated with failure of fibre decussation in the superior cerebellar peduncles and pyramidal tracts and varying degrees of vermian agenesis. ${ }^{1}$ As a result, the thickened superior cerebellar peduncles run a more horizontal course between the brainstem and cerebellum. More than 10 different gene mutations have been associated with Joubert syndrome, making it a very

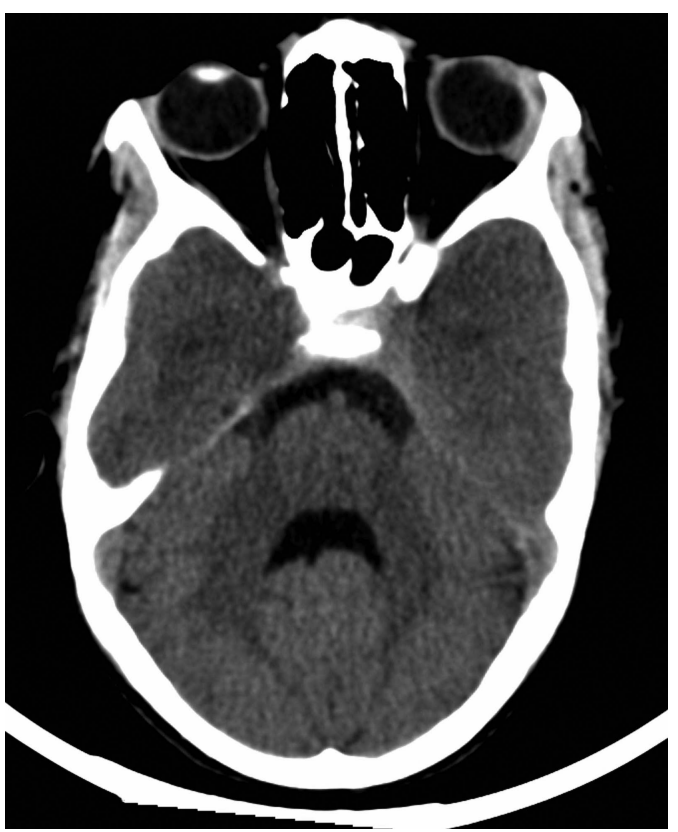

Figure 3 Axial CT section showing a 'batwing' configuration of the fourth ventricle and an enlarged prepontine cistern. The cerebellum and pons appear normal. 


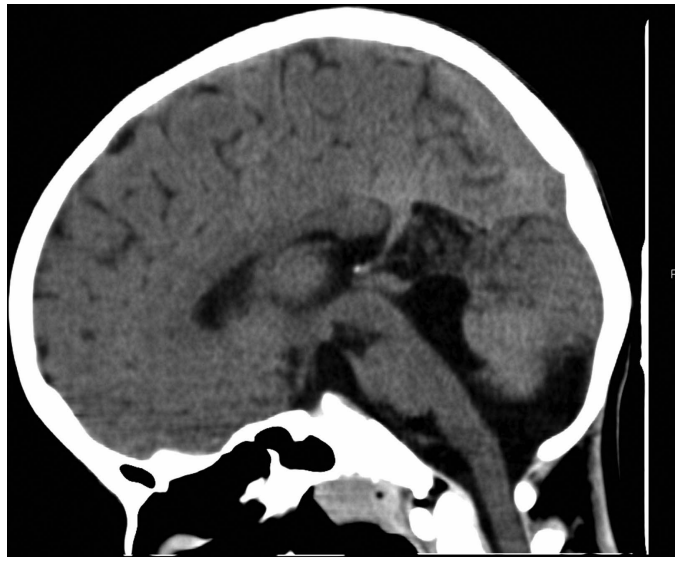

Figure 4 Sagittal CT section showing an enlarged deformed fourth ventricle, hypoplastic vermis and deepened interpeduncular fossa. The corpus callosum appears normal.

heterogeneous disorder. Patients present with an abnormal respiration pattern at birth and during infancy. Individuals who survive have ataxia, hypotonia, nystagmus, oculomotor apraxia and mental retardation. ${ }^{2}$

Joubert syndrome may be classified into two types based on the presence or absence of retinal dysplasia. ${ }^{3}$ There are several systemic associations with Joubert syndrome such as coloboma, retinal dysplasia, multicystic dysplastic kidney, hepatic fibrosis and polydactyly. ${ }^{4}$

The presence of the molar tooth sign and vermian hypoplasia is a hallmark for the diagnosis of Joubert syndrome. ${ }^{4}$ The molar tooth sign is a result of abnormally oriented thickened superior cerebellar peduncles and a widened interpeduncular fossa. The fourth ventricle is enlarged and distorted, giving rise to the batwing appearance. Other findings which include morphological abnormalities of the brainstem and cerebellum, corpus callosal dysgenesis, posterior fossa enlargement, increased retrocerebellar CSF, ventriculomegaly and migration disorders are present to varying degrees. ${ }^{5}$
Joubert syndrome is associated with poor prognosis. Treatment is generally supportive, depending on the presence of neurological deficits and cognitive impairment. These individuals are very sensitive to respiratory depressants, and therefore medication should be administered with caution. ${ }^{6}$

\section{Learning points}

- The presence of a molar tooth sign and a batwing appearance of the fourth ventricle with appropriate clinical findings is characteristic of Joubert syndrome.

- Joubert syndrome can manifest with a number of central nervous system and systemic abnormalities. Hence, a thorough search should be made to look for any syndromal associations in a suspected case.

\section{Competing interests None.}

\section{Patient consent Obtained.}

Provenance and peer review Not commissioned; externally peer reviewed.

\section{REFERENCES}

1 Spampinato MV, Kraas J, Maria BL, et al. Absence of decussation of the superior cerebellar peduncles in patients with Joubert syndrome. Am J Med Genet A 2008;146A:1389-94.

2 Joubert M, Eisenring JJ, Robb JP, et al. Familial agenesis of the cerebellar vermis. A syndrome of episodic hyperpnea, abnormal eye movements, ataxia and retardation. Neurology 1969;19:813-25.

3 Kendell B, Kingsley D, Lambert SR, et al. Joubert's syndrome; a clinicoradiological study. Neuroradiology 1990;31:502-6.

4 Maria BL, Hoang KB, Tusa RJ, et al. "Joubert syndrome" revisited: key ocular motor signs with magnetic resonance imaging correlation. J Child Neurol 1997;12:423-30.

5 Poretti A, Huisman TAGM, Scheer I, et al. Joubert syndrome and related disorders: spectrum of neuroimaging findings in 75 patients. AJNR Am J Neuroradiol 2011;32:1459-63.

6 Habre W, Sims C, D'Souze M, Anaesthetic management of children with Joubert's syndrome. Paediatr Anaesth 1997;7:251-3.

Copyright 2014 BMJ Publishing Group. All rights reserved. For permission to reuse any of this content visit

http://group.bmj.com/group/rights-licensing/permissions.

BMJ Case Report Fellows may re-use this article for personal use and teaching without any further permission.

Become a Fellow of BMJ Case Reports today and you can:

- Submit as many cases as you like

- Enjoy fast sympathetic peer review and rapid publication of accepted articles

- Access all the published articles

- Re-use any of the published material for personal use and teaching without further permission

For information on Institutional Fellowships contact consortiasales@bmjgroup.com

Visit casereports.bmj.com for more articles like this and to become a Fellow 